\title{
Commentary: Does a stitch in time still save nine? Sutureless valves take aim at the proverb
}

\author{
Lawrence M. Wei, MD, Harold G. Roberts, MD, and Vinay Badhwar, MD
}

\author{
From the Department of Cardiovascular and Thoracic Surgery, West Virginia University, Morgantown, WVa. \\ Disclosures: Authors have nothing to disclose with regard to commercial support. \\ Received for publication Sept 3, 2018; accepted for publication Sept 4, 2018; available ahead of print Oct 23, \\ 2018. \\ Address for reprints: Vinay Badhwar, MD, Department of Cardiovascular and Thoracic Surgery, West Virginia \\ University, 1 Medical Center Dr, Morgantown, WV 26506 (E-mail: vinay.badhwar@wvumedicine.org). \\ J Thorac Cardiovasc Surg 2019;157:1783-4 \\ $0022-5223 / \$ 36.00$ \\ Copyright (C) 2018 by The American Association for Thoracic Surgery \\ https://doi.org/10.1016/j.jtcvs.2018.09.007
}

In this issue of the Journal, Suri and colleagues ${ }^{1}$ present the $^{-}$ 1-year results of the US Food and Drug Administration Investigational Device Exemption trial sponsored by LivaNova to evaluate the Perceval sutureless aortic valve (LivaNova PLC, London, United Kingdom). In this well-written and diligently prepared report, 289 of 300 $(96.3 \%)$ attempted valve implantations were documented as successful. Operative and 1-year mortalities were 1.3\% and $5.2 \%$, respectively, lower than predicted by the Society of Thoracic Surgeons estimated risk. As expected with successful relief of aortic stenosis, patients showed improvement in clinical status and left ventricular mass regression, with mean gradients of $11.8 \mathrm{~mm} \mathrm{Hg}$ at discharge and $9.6 \mathrm{~mm} \mathrm{Hg}$ at 1 year. Suri and colleagues ${ }^{1}$ appropriately conclude that the study results confirm the safety and efficacy of the Perceval sutureless aortic valve.

Although this exciting valve may be sutureless, it is not flawless. Paravalvular leaks and acute valve dislodgment accounted for 6 of the 11 failed implantations. The paravalvular leak rate is higher than expected with sutured valves and is comparable to outcomes of transcatheter aortic valve replacement. ${ }^{2,3}$ Three patients (1\%) had major aortic root complications including dissection necessitating valve removal or aortic root replacement, extremely rare with sutured aortic valve replacement. Suri and colleagues ${ }^{1}$ surmised that these complications may have been the result of full-thickness débridement of the annulus early in the learning curve of operators, instead of the nitinol expansion of the sutureless prosthesis or valve oversizing. Although this may be true, it signals a slight warning to surgeons with limited aortic experience who are considering adopting this technology. Finally, the rate of permanent pacemaker implantation was $10.7 \%$, considerably higher than reported with sutured aortic valve replacement. ${ }^{4}$ As one evaluates the relative significance of this issue, there is evidence that permanent pacing after aortic valve replacement may be detrimental to survival, 5,6 raising the possibility that the high rate of pacemaker

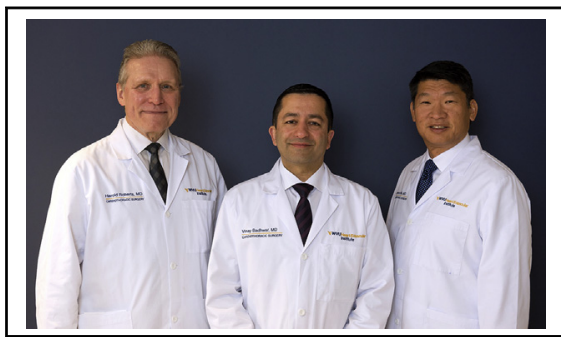

Left to right. Harold G. Roberts, MD, Vinay Badhwar $\mathrm{MD}$, and Lawrence M. Wei, MD

\section{Central Message}

As we welcome advancing technology in the surgical management of aortic stenosis, one must recognize that valves may be sutureless, not flawless.

See Article page 1773 .

implantation may result in lower long-term survival. In defense of this observation, some preliminary data may link sutureless valve oversizing to increased pacemaker rate and a possible reduction in pacemaker rate attributed to more conservative sizing.

The purported advantages of sutureless versus sutured valves include excellent hemodynamic performance, relative ease of implantation and shorter operative and ischemic times. The actual transvalvular gradients reported in this study, however, were similar to those achievable with currently available sutured bioprostheses. ${ }^{2}$ The operative and ischemic times were relatively short, but not markedly faster than those attainable by experienced surgeons implanting a sutured valve-an observation shared by our personal experience with the prosthesis. Nevertheless, this valve may have some cumulative advantages in minimal access aortic valve replacement or those with root calcification. Despite potential advantages, sutureless valves are currently more expensive than sutured bioprostheses. In the United States, there is a current financial offset offered to hospitals through the Centers for Medicare and Medicaid Services New Technology Add-on Payment, which adds an additional payment of approximately $\$ 6000$ to the normal Diagnosis Related Group hospital payment. This has enabled surgeons and hospitals to gain experience with this relatively new technology in a relatively cost neutral environment. But 
what will happen when the New Technology Add-on Payment expires in the near future?

Suri and colleagues ${ }^{1}$ are to be commended for this contribution leading to the Food and Drug Administration approval of the Perceval sutureless prosthesis while simultaneously providing valuable knowledge to advance the surgical management of aortic stenosis. What niche will the sutureless valve fill in the prosthetic armamentarium available to treat aortic stenosis? Perhaps it will facilitate widespread adoption of minimally invasive aortic valve replacement techniques, including right anterior thoracotomy or robotically assisted approaches. The short-term results reported in this study demonstrate the safety of the Perceval valve, but longer follow-up will be needed to determine whether savings in operative time will offset the cost and the risks of permanent pacemaker implantation and annular complications. In 1797, English astronomer Francis Baily reportedly coined the term "a stitch in time saves nine," which later became ingrained in English work ethic to mean that prompt correction of a defect may save time later when or if the defect were to enlarge. Although the introduction of the sutureless valve is a clear advancement in the surgical management of aortic valve disease, has it disproved the proverb? Not quite yet.

\section{References}

1. Suri RM, Javadikasgari H, Heimansohn DA, Weissman NJ, Ailawadi G, Ad N, et al. Prospective US investigational device exemption trial of a sutureless aortic bioprosthesis: one-year outcomes. J Thorac Cardiovasc Surg. 2019;157: 1773-82.e3.

2. Goldman S, Cheung A, Bavaria JE, Petracek MR, Groh MA, Schaff HV. Midterm, multicenter clinical and hemodynamic results for the Trifecta aortic pericardial valve. J Thorac Cardiovasc Surg. 2017;153:561-9.e2.

3. Blanke P, Pibarot P, Hahn R, Weissman N, Kodali S, Thourani V, et al. Computed tomography-based oversizing degrees and incidence of paravalvular regurgitation of a new generation transcatheter heart valve. JACC Cardiovasc Interv. 2017;10: 810-20.

4. Bagur R, Manazzoni JM, Dumont É, Doyle D, Perron J, Dagenais F, et al. Permanent pacemaker implantation following isolated aortic valve replacement in a large cohort of elderly patients with severe aortic stenosis. Heart. 2011;97: $1687-94$.

5. Ensminger S, Fujita B, Bauer T, Möllmann H, Beckmann A, Bekeredjian R, et al; GARY Executive Board. Rapid deployment versus conventional bioprosthetic valve replacement for aortic stenosis. J Am Coll Cardiol. 2018;71:1417-28.

6. Greason KL, Lahr BD, Stulak JM, Cha YM, Rea RF, Schaff HV, et al. Long-term mortality effect of early pacemaker implantation after surgical aortic valve replacement. Ann Thorac Surg. 2017;104:1259-64.

7. Di Eusanio M, Phan K, Berretta P, Carrel TP, Andreas M, Santarpino G, et al. Sutureless and Rapid-Deployment Aortic Valve Replacement International Registry (SURD-IR): early results from 3343 patients. Eur J Cardiothorac Surg. 2018;54:768-73. 